\title{
Diabetes in the Torres Strait Islands of Australia: better clinical systems but significant increase in weight and other risk conditions among adults, 1999-2005
}

\author{
Robyn A McDermott, Bradley G McCulloch, Sandra K Campbell and Dallas M Young
}

T orres Strait Islanders have the highest prevalence of type 2 diabetes in Australia, with about a third of adults affected. ${ }^{1}$ In June 1996, the Torres Strait and Northern Peninsula Area (TS\&NPA) District Health Council convened a summit on diabetes that included members of each Island community, health staff and experts in the field of diabetes care and prevention. One of the five strategies proposed in the resulting "Meriba Zageth for diabetes" plan was improving the quality and scope of primary and secondary clinical care in the TS\&NPA District. ${ }^{2}$ A detailed history of subsequent developments is given in Box 1 .

Between 1999 and 2003, more than 300 new patients with diabetes were added to the clinic registers. In subsequent years, numbers on the registers increased, and by 2006, useful reports were being generated from the information system (Project Ferret, Pen Computer Systems, Sydney, NSW; see Box 1) for each clinic. At the same time, communitybased chronic disease risk factor surveys were being undertaken in the District, and baseline results were used for service planning, including programs to improve early detection and prevention of diabetes, heart and renal disease and sexually transmitted infections. ${ }^{3}$ These surveys found extremely high crude prevalence of the metabolic syndrome (43.5\% in Torres Strait Islander men and $52.9 \%$ in women, by the American National Education Program Third Adult Treatment Panel criteria). ${ }^{4}$

Here, we review (i) the current status of primary level diabetes indicators in the District and (ii) changes in metabolic risk factors in a cohort of adults without diabetes followed from 2000-01 to 2005-06. Incidence of diabetes has not previously been reported in this population.

\section{METHODS}

Data from clinical records of those registered as having diabetes were extracted manually for years 1999 and 2002, then downloaded from the primary care information system for 2004 and 2005. Data quality for the latter period was checked

\section{ABSTRACT}

Objectives: To (i) assess changes in clinical indicators of adults diagnosed with diabetes and (ii) estimate changes in risk factors and incidence of diabetes among adults without diabetes living in the Torres Strait and Northern Peninsula Area Health Service District in Queensland from 1999 to 2005.

Design and participants: (i) Annual audit of clinical records of Torres Strait Islander adults on diabetes registers in 21 primary care clinics, and (ii) a 5-year follow up of a community cohort of 207 Torres Strait Islander adults without diabetes who participated in the Well Person's Health Check in 2000-01 and 2005-06.

Main outcome measures: Weight, height, waist circumference, fasting blood sugar (those without diabetes) and glycated haemoglobin ( $\mathrm{HbA}_{1}$; those with diabetes) levels, blood pressure (BP), fasting triglyceride and high-density lipoprotein cholesterol levels, urinary albumin-to-creatinine ratio and smoking status.

Results: The number of adults included on the diabetes register increased from 555 in 1999 to 1024 in 2005. The mean age of patients diagnosed with diabetes decreased from 53.3 to 51.5 years, and their mean weight increased from $86.8 \mathrm{~kg}$ to $95.6 \mathrm{~kg}$. Mean $\mathrm{HbA}_{1 \mathrm{c}}$ level remained unchanged at about $9 \%$, but the proportion with $\mathrm{HbA}_{1 \mathrm{c}}$ level $<7 \%$ increased from $18.4 \%$ to $26.1 \%$, and the proportion prescribed insulin increased from $14 \%$ in 2002 to $22 \%$ in 2005. The proportion with BP $<140 / 90 \mathrm{mmHg}$ increased from $40.3 \%$ in 1999 to $66.8 \%$ in 2005. In the sample of 207 adults without diabetes, from 2000 to 2006, there was a weight gain of about $1 \mathrm{~kg}$ per person per year, and an annual increase in waist circumference of $0.8 \mathrm{~cm}$ in men and $1.2 \mathrm{~cm}$ in women. Crude incidence of diabetes was 29 (95\% Cl, 19-41) per 1000 person-years. There was a significant increase in diastolic blood pressure and fasting blood sugar levels, and no change in smoking habits.

Conclusions: Clinical care of adults with diabetes has improved and more people with diabetes are being diagnosed. However, weight gain and high rates of glycaemia remain a challenge and will result in a large burden of complications, including renal failure. Incidence data from this sample extrapolate to 120 (95\% Cl, 103-147) new cases of diabetes in the District each year. Urgent action to improve nutrition, decrease smoking and increase physical activity is required to improve metabolic fitness in younger people.

For editorial comment, see page 494 MJA 2007; 186: 505-508

against the clinic file in a random subsample of 100 records in the diabetes register in 2005, looking at blood pressure (BP), weight, waist circumference, glycated haemoglobin $\left(\mathrm{HbA}_{1 \mathrm{c}}\right)$ level, foot check, lipid and serum creatinine levels and vaccination status. These checks found variable underreporting on the computerised system (compared with manual files) of between $5 \%\left(\mathrm{HbA}_{1 \mathrm{c}}\right)$ and $40 \%$ (waist circumference). Information on insulin use was recorded in the computerised system only for Thursday Island in 2005 (for 416 patients). Where there was more than one measure recorded in a single year for a client (eg, $\mathrm{BP}$ or $\mathrm{HbA}_{1 \mathrm{c}}$ ), the most recent measure was used.

\section{Follow-up of cohort without diabetes}

Of 478 adults in four communities who were designated free of diabetes in a comprehensive check-up in 2000-01, 207 (43\%) volunteered for a 5-year follow-up health check in 2005-06. Fasting blood was taken for estimation of blood sugar, and total and high-density lipoprotein (HDL) cholesterol and triglyceride levels. Resting BP, weight, height and waist circumference were estimated using standard methods. ${ }^{3}$ Those with a fasting blood sugar level of $5 \mathrm{mmol} / \mathrm{L}$ or more were checked with a fasting $75 \mathrm{~g}$ oral glucose tolerance test. Diabetes was classified according to World Health Organization criteria. 


\section{DIABETES}

1 History of improvements to clinical care for diabetes in the Torres Strait and Northern Peninsula Area District

1999 Major changes to primary services in the 21 clinics served by Queensland Health in the District, including:

- a visiting diabetes outreach specialist team;

- evidence-based diabetes screening and referral and management protocols;

- registers and recall systems managed by local Indigenous health workers;

- clear roles and responsibilities for health workers in chronic disease management, including orientation and regular professional updates;

- an information system integrating care plans for a range of common chronic conditions; and

- an audit and feedback system for quality improvement.

2001 Queensland Health approved and adapted a computerised health information system (Project Ferret, Pen Computer Systems, Sydney, NSW) to be used in all Indigenous primary care settings. The system has since been installed in more than 50 community clinics in Queensland, predominantly in the northern areas. It keeps all data on a central server, and remote real-time access from clinics allows updating of clinical data wherever clients are seen. As Queensland Health is the sole provider of health services to the District, the information system captures the whole population in the District who are considered "regulars" (ie, not transient, who live mostly in the District).

2004 The system began to report customised de-identified reports, which can be generated by clinic, condition, age group, and sex. These are used by staff and management in the District to monitor the performance of the primary care service for priority conditions (eg, diabetes, renal, cardiovascular disease, rheumatic heart disease).

200612765 "regular" clients were registered on the system for the District.

2 Key diabetes measures, Torres Strait diabetes registers, 1999-2005

\begin{tabular}{|c|c|c|c|c|c|}
\hline Measure & 1999* & $2002^{*}$ & $2004^{\dagger}$ & $2005^{\dagger}$ & $\begin{array}{c}P \\
\text { (trend) }\end{array}$ \\
\hline Number of patients & 555 & 921 & 1017 & 1024 & \\
\hline Age & 53.3 & 52.4 & 52.5 & 51.5 & $<0.01$ \\
\hline Weight (SD) & $86.8 \mathrm{~kg}(18.2)$ & $91.3 \mathrm{~kg}(20.0)$ & $94.9 \mathrm{~kg}(21)$ & $95.6 \mathrm{~kg}(23)$ & $<0.01$ \\
\hline Body mass index (SD) & $32.5(6.5)$ & $32.9(6.3)$ & $34.5(12.1)$ & $35.0(11.5)$ & ns \\
\hline Waist circumference (SD) & na & na & $105.7 \mathrm{~cm}(47)$ & $110.9 \mathrm{~cm}(21.3)$ & 0.03 \\
\hline $\mathrm{HbA}_{1 \mathrm{c}}$ level (SD) & $9.2 \%(2.2)$ & $9.0 \%(2.3)$ & $9.14 \%(2.4)$ & $9.0 \%(2.3)$ & ns \\
\hline $\begin{array}{l}\text { Percentage with } \\
\mathrm{HbA}_{1 \mathrm{c}}<7 \%\end{array}$ & $18.4 \%$ & $24.5 \%$ & $23.5 \%$ & $26.1 \%$ & $<0.01$ \\
\hline \multicolumn{6}{|l|}{ Blood pressure } \\
\hline Systolic $(\mathrm{mmHg})$ & 132.6 & 129.9 & 126.9 & 129.0 & ns \\
\hline Diastolic (mmHg) & 79.1 & 76.9 & 76.5 & 76.8 & ns \\
\hline $\begin{array}{l}\text { Percentage with blood } \\
\text { pressure }<140 / 90 \mathrm{mmHg}\end{array}$ & $40.3 \%$ & $63.7 \%$ & $66.3 \%$ & $66.8 \%$ & ns \\
\hline Median urinary $A C R$ & na & 6.8 & 7.1 & 5.9 & ns \\
\hline $\begin{array}{l}\text { Percentage receiving } \\
\text { insulin treatment }\end{array}$ & & $14 \% *$ & & $22 \% \ddagger$ & na \\
\hline
\end{tabular}

* Manual audit of clinic records. † Reports downloaded from Project Ferret in May 2006. ‡ Data available for Thursday Island only for 2005.

$\mathrm{HbA}_{1 \mathrm{c}}=$ glycated haemoglobin. $\mathrm{ACR}=$ albumin-to-creatinine ratio. $\mathrm{na}=$ not applicable. $\mathrm{ns}=$ not significant at 0.05 level.

\section{Statistical analysis}

Data were analysed with SPSS (version 11.0 for Windows; SPSS Inc, Chicago, Ill, USA) and Stata (version 7.0; StataCorp, College Station, Tex, USA) software; $\chi^{2}$ and $t$ tests were used to compare proportions and body mass index (BMI). Where data were not normally distributed, non-parametric tests were used (Kruskal-Wallis). $\chi^{2}$ tests and one-way analysis of variance were used to test for trend.

\section{Ethical approval}

Our research received approval from James Cook University and Cairns Base Hospital Ethics Committees in 2002, with support from the Torres Strait Health Council in 2004. The data presented here have been discussed with the Torres Strait Health Council and Regional Authority.

\section{RESULTS}

\section{Clinical care for adults with diabetes}

Since 1999, the number of adults with diabetes on the registers almost doubled, from 555 to 1024 . This was fewer than half the expected number of adults with diabetes extrapolated from community surveys based on the clinic-registered population of 12765. At the same time, there was an apparent decrease in mean age of people with diabetes on the registers (as more younger people were being diagnosed), together with a significant increase in mean weight, waist circumference and BMI, from an already high baseline. Completeness of recording varied between age (100\%), weight $(86 \%)$, waist circumference $(30 \%)$, $\mathrm{HbA}_{1 \mathrm{c}}$ level (82\%), BP (92\%) and urinary albumin-to-creatinine ratio (57\%). There was an increase in the proportion of patients with diabetes whose glycaemia was adequately controlled $\left(\mathrm{HbA}_{1 \mathrm{c}}<7 \%\right)$, and an increase in the proportion taking insulin, although mean $\mathrm{HbA}_{1 \mathrm{c}}$ level did not appear to improve. BP control improved, with nearly two-thirds achieving a BP less than $140 / 90 \mathrm{mmHg}$. Marked improvements in intermediate indicators reported in 2002 appear to have levelled off a little in 2004 and 2005 (Box 2).

\section{Changes in risk factors and incident diabetes in adults without diabetes}

The 207 adults from four communities who participated in the follow-up health check were slightly older (mean age at baseline, 35 years [95\% CI, 33-37 years] v 32 years [95\% CI, 30-34 years] for those not followed up), and heavier (baseline BMI, 31 [95\% CI, 29-32] v 29 [95\% CI, 28-31]).

In these adults, there was weight gain of almost $1 \mathrm{~kg}$ per year per person, and a mean annual increase in waist circumference of 


\section{DIABETES}

\begin{tabular}{|c|c|c|c|c|}
\hline Risk factor & Baseline value $(95 \% \mathrm{Cl})$ & Follow-up value (95\% Cl) & Mean difference $(95 \% \mathrm{Cl})$ & $P^{*}$ \\
\hline \multicolumn{5}{|l|}{ Men $(n=103)$} \\
\hline Age (years) & $37.7(34.8-40.7)$ & $42.7(39.8-45.7)$ & 5.6 years & na \\
\hline Weight (kg) & $89.4(85.2-93.5)$ & $94.0(89.8-98.3)$ & 4.76 (2.87 to 6.65$)$ & $<0.01$ \\
\hline Waist (cm) & $101.2(97.9-104.5)$ & $105.0(101.6-108.4)$ & 3.8 (1.9 to 5.8$)$ & $<0.01$ \\
\hline Fasting blood glucose level (mmol/L) & $4.9(4.8-5.1)$ & $5.6(5.2-6.1)$ & 0.7 (0.3 to 1.2$)$ & $<0.01$ \\
\hline Systolic blood pressure $(\mathrm{mmHg})$ & $136(132-138)$ & $133(129-137)$ & $-2.8(-6.4$ to 0.9$)$ & ns \\
\hline Diastolic blood pressure $(\mathrm{mmHg})$ & $73(70-75)$ & $78(76-80)$ & 5.4 (2.9 to 8.0$)$ & $<0.01$ \\
\hline Urinary ACR & $8.1(3.3-12.9)$ & $12.5(0.7-24.3)$ & $4.4(-6.2$ to 15.1$)$ & ns \\
\hline Fasting triglyceride level (mmol/L) & $1.8(1.5-2.1)$ & $2.0(1.5-2.6)$ & $0.23(-1.7$ to 0.64$)$ & ns \\
\hline Fasting HDL cholesterol level (mmol/L) & $1.1(1.0-1.2)$ & $1.1(1.0-1.1)$ & $0.017(-0.27$ to 0.061$)$ & ns \\
\hline No. of smokers $(\%)^{\dagger}$ & $53(51.5 \%)$ & $50(48.5 \%)$ & & \\
\hline \multicolumn{5}{|l|}{ Women $(n=104)$} \\
\hline Age (years) & $31.5(29.1-33.9)$ & $36.5(34.7-38.9)$ & 5.3 years & na \\
\hline Weight (kg) & $85.8(81.8-89.8)$ & $91.2(87.3-95.0)$ & $5.6(3.7$ to 7.5$)$ & $<0.01$ \\
\hline Waist $(\mathrm{cm})$ & $103.8(100.4-107.2)$ & $110.9(106.8-115.0)$ & 7.08 (3.7 to 10.5$)$ & $<0.01$ \\
\hline Fasting blood glucose level (mmol/L) & $5.0(4.82-5.10)$ & $5.5(5.08-5.91)$ & 0.54 (0.15 to 0.92$)$ & $<0.01$ \\
\hline Systolic blood pressure $(\mathrm{mmHg})$ & $122.3(119.3-125.2)$ & $118(115.9-121.8)$ & $-3.4(-6.0$ to 0.85$)$ & $<0.01$ \\
\hline Diastolic blood pressure $(\mathrm{mmHg})$ & $65.5(63.4-67.6)$ & $70.8(68.9-72.6)$ & 5.3 (3.1 to 7.4$)$ & $<0.01$ \\
\hline Urinary ACR & $5.8(2.6-9.1)$ & $6.7(3.3-10.0)$ & $0.83(-1.57$ to 3.22$)$ & ns \\
\hline Fasting triglyceride level (mmol/L) & $1.39(1.17-1.61)$ & $1.64(1.36-1.92)$ & $0.25(-0.01$ to 0.50$)$ & ns \\
\hline Fasting HDL cholesterol level (mmol/L) & $1.08(1.03-1.13)$ & $1.20(1.14-1.26)$ & 0.11 (0.06 to 0.16$)$ & $<0.01$ \\
\hline No. of smokers $(\%)^{\ddagger}$ & $50(48 \%)$ & $47(45.6 \%)$ & & \\
\hline
\end{tabular}

$0.8 \mathrm{~cm}$ for men and $1.2 \mathrm{~cm}$ for women. Their fasting levels of blood glucose increased significantly as did their diastolic blood pressure. Albuminuria and fasting triglyceride levels were unchanged. HDL cholesterol levels improved in women, but not in men (Box 3). High rates of tobacco smoking showed no change. Thirty new cases of diabetes were observed in this group during the 5-year interval, giving a crude incidence rate of 29 per 1000 person-years (95\% CI, 20-41 person-years). Based on 2001 census data, this translates to about 120 (95\% CI, 103-147) new cases of type 2 diabetes per year among people without diabetes aged 15 or over in the District. Baseline mean waist circumference among those with incident diabetes was $115.1 \mathrm{~cm}$ (95\% CI, $107.4-122.8 \mathrm{~cm}$ ) compared with a mean baseline waist circumference of $98.4 \mathrm{~cm}(95 \% \mathrm{CI}, 95.1-101.8 \mathrm{~cm})$ for those who did not develop diabetes in the interval. Those with a baseline waist circumference of $113.1 \mathrm{~cm}$ or more were 67 times (95\% CI, 6-129 times) more likely to develop diabetes over the 5 years than those whose waist circumference was less than $102 \mathrm{~cm}$ at baseline. In this group, tobacco smoking at baseline was not a significant predictor of incident diabetes (OR, 0.8; 95\% CI, 0.3-1.3).

\section{DISCUSSION}

Since 1999 in the TS\&NPA, there have been significant improvements in systems for early detection and case management of people with diabetes and other chronic conditions, including the introduction of a District-wide computerised primary care information system that provides population-level support for care plans, disease registers, patient recall and reports on quality of care for priority conditions. This is in line with current best practice in community level chronic care, ${ }^{5}$ although there remain problems with system and health staff support, and these require continuous attention.

The improvement in glycaemic control from a very poor baseline shown here is similar to preliminary results from other
Indigenous Australian services. The "Audit and Best practice for Chronic Disease" (ABCD) project in the Northern Territory recently reported improved systems of chronic care in 12 Indigenous communities where the proportion of people with diabetes with $\mathrm{HbA}_{1 \mathrm{c}}$ levels less than 7\% increased from 19\% at baseline to $28 \%$ by the third year. ${ }^{6}$ Also, the Quality Assurance for Aboriginal Medical Services Program reported an improvement in mean $\mathrm{HbA}_{1 \mathrm{c}}$ level from $9.3 \%$ to $8.6 \%$ among 74 Aboriginal people with diabetes in two remote communities after 12 months of intensive intervention involving point-of-care testing for $\mathrm{HbA}_{1 \mathrm{c}}$ with immediate client feedback and counselling. ${ }^{7}$

However, great disparities remain between reported glycaemia in Indigenous people compared with the general Australian population of people with diabetes, where 38\% achieved an $\mathrm{HbA}_{\mathrm{lc}}$ level of less than $7 \%$. $^{8}$ The Indian Health Service in the United States has made significant improvements in glycaemic control (from a mean $\mathrm{HbA}_{1 \mathrm{c}}$ level of $8.9 \%$ in 1995 to 
7.9\% in 2001) and in other intermediate clinical outcomes, resulting from increased resource allocation for quality improvement in diabetes care. ${ }^{9}$ Nonetheless, African-Americans in the US have reported levels of $\mathrm{HbA}_{1 \mathrm{c}}$ about $0.65 \%$ higher than those of non-Hispanic white people with diabetes, ${ }^{10}$ although recent reports suggest that this can be improved with targeted community-level interventions. For example, in North Carolina two communities were able to show a shift in the proportion of people with diabetes with a reported $\mathrm{HbA}_{1 \mathrm{c}}$ level less than $7 \%$ from $20.8 \%$ in 1997 to $44.3 \%$ in 2004. Interestingly, in this study of black Americans with predominantly low socioeconomic status, smoking rates remained unchanged at about $46 \%$, similar to the rates we report here. ${ }^{11}$

In contrast with these improvements in community-level clinical care services, there appear to be few successful corresponding systematic interventions dealing with the causes of diabetes in the population, particularly central obesity, poor quality food and tobacco use. The incidence of diabetes in the Torres Strait that we report here is 50\% higher than that reported in a cohort of Aboriginal adults from central Australia a decade ago. ${ }^{12}$ As our sample was small and only $43 \%$ of the original cohort were followed up, and as those followed up were slightly older and heavier at baseline than those who were not, our reported incidence could be an overestimate. Our study was underpowered to find an impact of tobacco smoking on risk of diabetes. In remote parts of Australia, the availability and affordability of healthy food have decreased from what was an already poor position. People in very remote areas of Queensland pay an average of $\$ 114$ per fortnight more than people living in cities for a very basic family food basket, and have faced higher increases in food prices than the consumer price index, although the price of tobacco is not different from metropolitan areas. $^{13}$

Tobacco smoking has been reported to have a role in incident diabetes in Japanese men ${ }^{14,15}$ (although large cohort studies have not confirmed this in European populations ${ }^{16}$ ) and in excess complications in established diabetes, particularly renal disease. ${ }^{17}$ The few community interventions to reduce the extremely high rates of Indigenous tobacco use in Australia that have been reported so far show modest impact, ${ }^{18,19}$ and central obesity appears to be intractable everywhere.

On the bright side, the improvements in clinical systems demonstrated here and elsewhere in Aboriginal Health Services show that major changes are possible. There is an urgent need to get whole communities to eat a healthier diet and get fitter metabolically so they can lose central adiposity and reduce blood sugar levels. In people with diabetes, for every $1 \%$ fall in $\mathrm{HbA}_{1 \mathrm{c}}$ level, there can be a corresponding $38 \%$ reduction in microvascular complications, ${ }^{20}$ and it is clear that more intensive management of glycaemia (and other risk factors) is needed in this group. ${ }^{21}$ At the same time, a much higher proportion of the community has features of the metabolic syndrome. This situation demands innovative and ongoing population-level interventions which have demonstrated effectiveness and are highly cost-effective. ${ }^{22}$

\section{ACKNOWLEDGEMENTS}

These studies were funded by National Health and Medical Research Council project grants. Thanks to Rohan Pratt for data extraction, Adrian Esterman for statistical advice, and staff from the Torres Strait and Northern Peninsula Area Health Service District for ongoing collaboration.

\section{COMPETING INTERESTS}

None identified.

\section{AUTHOR DETAILS}

Robyn A McDermott, MB BS, MPH, FAFPHM, Pro-Vice Chancellor ${ }^{1}$

Bradley G McCulloch, BSc, MPH, Senior Epidemiologist ${ }^{2}$

Sandra K Campbell, RN, MAE, Research Fellow ${ }^{3}$

Dallas M Young, BAppSc, MHP, Manager,

Public Health Research Program ${ }^{3}$

1 Division of Health Sciences, University of

South Australia, Adelaide, SA.

2 Tropical Public Health Unit Network,

Queensland Health, Cairns, QLD.

3 James Cook University, Cairns, QLD.

Correspondence:

Robyn.Mcdermott@unisa.edu.au

\section{REFERENCES}

1 Leonard D, McDermott R, O'Dea K, et al. Obesity, diabetes and associated cardiovascular risk factors among Torres Strait Islander people. Aust N Z J Public Health 2002; 26: 144-149.

2 Torres Strait and Northern Peninsula Area Health Council. Meriba Zageth for Diabetes: our work for diabetes. Cairns: Queensland Health, 1996.

3 Miller G, McDermott R, McCulloch B, et al. The Well Person's Health Check: a population screening program in Indigenous communities in north Queensland. Aust Health Rev 2002; 25: 140-151.

4 McDermott R. Diabetes and the metabolic syndrome among Torres Strait Islanders: report to the Torres Strait Health Council. Cairns: Tropical Public Health Unit, Queensland Health, 2005.

5 Sequist T, Cullen T, Ayanian J. Information technology as a tool to improve the quality of American Indian Health Care. Am J Public Health 2005; 95: 2173-2179.
6 Bailie R, Dowden M, Si D, et al. Audit and best practice for chronic disease. Project progress report. Darwin: Menzies School of Health Research, 2005. http://www.health.gov.au/internet/h4l/publishing.nsf/Content/162F4DCC 6C18E18CCA2571950002F331/\$File/ABCD\% 20Report.pdf (accessed Apr 2007).

7 Shephard M. Cultural and clinical effectiveness of the "QAAMS" point-of-care testing model for diabetes management in Australian Aboriginal medical services. Clin Biochem Rev 2006; 27: 161 170.

8 National Association of Diabetes Centres. Final report of the Australian National Diabetes Information Audit and Benchmarking (ANDIAB). Canberra: Australian Government Department of Health and Ageing, 2004. http://www.health.gov.au/internet/ wcms/publishing.nsf/Content/pq-diabetes-pubsandiab04 (accessed Apr 2007).

9 Wilson C, Gilliland S, Cullen T, et al. Diabetes outcomes in the Indian health service during the era of the Special Diabetes Program for Indians and the Government Performance and Results Act. Am J Public Health 2005; 95: 1518-1522.

10 Kirk J, D'Agostino RB Jr, Bell RA, et al. Disparities in $\mathrm{HbA1c}$ levels between African-American and nonHispanic white adults with diabetes: a meta-analysis. Diabetes Care 2006; 29: 2130-2136.

11 Rutledge S, Gregg EW,Beckles G, Williams DE. Improvement in lipid and glycated hemoglobin control among black adults with diabetes Raleigh and Greensboro, North Carolina, 1997. 2004. MMWR Morb Mortal Wkly Rep 2006; 55: 1248-1251.

12 Daniel M, Rowley KG, McDermott R, et al. Diabetes incidence in an Australian Aboriginal population: an 8-year follow-up study. Diabetes Care 1999; 22: 1993-1998.

13 Harrison MS, Coyne T, Lee AJ, et al. The increasing cost of the basic foods required to promote health in Queensland. Med J Aust 2007; 186: 9-14.

14 Will JC, Galuska DA, Ford ES, et al. Cigarette smoking and diabetes mellitus: evidence of a positive association from a large prospective cohort study. Int J Epidemiol 2001; 30: 540-546.

15 Wannamethee SG, Shaper AG, Pery IJ. Smoking as a modifiable risk factor for type 2 diabetes. Diabetes Care 2001; 24: 1590-1595.

16 Perry I, Wannamethee SG, Walker MK, et al. Prospective study of risk factors for development of non-insulin dependent diabetes in middle aged British men. BMJ 1995; 310: 560-564.

17 De Cosmo S, Lamacchia O, Rauseo A, et al. Cigarette smoking is associated with low glomerular filtration rate in male patients with type 2 diabetes. Diabetes Care 2006; 29: 2467-2470.

18 Ivers RG, Castro A, Parfitt D, et al. Evaluation of a multi-component community tobacco intervention in three remote Australian Aboriginal communities. Aust N Z J Public Health 2006; 30: 132-136.

19 Ivers RG. Indigenous Australians and tobacco: a literature review. Darwin: Menzies School of Health Research, 2001.

20 Intensive blood glucose control with sulphonylureas or insulin compared with conventional treatment and risk of complications in patients with type 2 diabetes mellitus. UK Prospective Diabetes Study Group. Lancet 1998; 352: 837-853.

21 Heine RJ, Diamant M, Mbanya JC, Nathan DM. Management of hyperglycaemia in type 2 diabetes: the end of recurrent failure? BMJ 2006; 333: 1200-1204.

22 Jacobs-van der Bruggen M, Bos G, Bemelmans WJ, et al. Lifestyle interventions are cost-effective in people with different levels of diabetes risk. Diabetes Care 2007; 30: 128-134.

(Received 23 Jan 2007, accepted 3 Apr 2007) 